\title{
Promoting Positive Technological Development in a Kindergarten Makerspace: A Qualitative Case Study
}

\author{
Amanda Strawhacker ${ }^{1 *}$, Marina Umaschi Bers ${ }^{1}$ \\ ${ }^{1}$ DevTech Research Group, Tufts University, 105 College Ave, Tufts University Medford, USA
}

*Corresponding Author: amanda.strawhacker@tufts.edu

Citation: Strawhacker, A. and Bers, M. U. (2018). Promoting Positive Technological Development in a Kindergarten Makerspace: A Qualitative Case Study. European Journal of STEM Education, 3(3), 09. https://doi.org/10.20897/ejsteme/3869

Published: September 6, 2018

\begin{abstract}
As education communities grow more interested in STEM (science, technology, engineering, and mathematics), schools have integrated more technology and engineering opportunities into their curricula. Makerspaces for all ages have emerged as a way to support STEM learning through creativity, community building, and hands-on learning. However, little research has evaluated the learning that happens in these spaces, especially in young children. One framework that has been used successfully as an evaluative tool in informal and technology-rich learning spaces is Positive Technological Development (PTD). PTD is an educational framework that describes positive behaviors children exhibit while engaging in digital learning experiences. In this exploratory case study, researchers observed children in a makerspace to determine whether the environment (the space and teachers) contributed to children's Positive Technological Development. $N=20$ children and teachers from a Kindergarten classroom were observed over 6 hours as they engaged in makerspace activities. The children's activity, teacher's facilitation, and the physical space were evaluated for alignment with the PTD framework. Results reveal that children showed high overall PTD engagement, and that teachers and the space supported children's learning in complementary aspects of PTD. Recommendations for practitioners hoping to design and implement a young children's makerspace are discussed.
\end{abstract}

Keywords: learning environments, makerspaces, positive technological development, early childhood STEM

\section{INTRODUCTION}

In the US and abroad, formal and informal learning spaces are becoming progressively more technology-rich and oriented toward STEM (science, technology, engineering, and mathematics) learning and $21^{\text {st }}$ century skills development (Bellanca, 2010; Breiner et al., 2012; Burke, 2014; Chang et al., 2015; National Research Council, 2013). As digitally-enriched learning approaches become more prevalent in education, schools are investing more money into dedicated STEM learning spaces and classrooms (Wang et al., 2016). It is urgent to understand the learning benefits of these novel learning spaces and materials. New advances in educational research have identified computational thinking practices, $21^{\text {st }}$ century skills, and technological literacy as content-specific learning outcomes that students are developing in these new learning environments (Bers, 2018; Bellanca, 2010; Bybee, 2000; Dakers, 2006). However, in addition to STEM content knowledge, research emphasizes the importance of developing character skills associated with this pedagogical shift towards technology integration, including collaborative problem-solving, design and inquiry cycles, and STEM identity development (Bers, 2012; Minner et 
al., 2012; Sullivan, 2016). Digital citizenship learning frameworks such as Ribble's Nine Elements of Digital Citizenship focus on teaching children to collaborate, communicate, and learn safely through technology, and to responsibly deal with ethical technology issues such as cyber bullying and protecting private information (Hollandsworth et al., 2011; Ribble, 2015). Traditional intervention methods struggle to capture the richness and complexity of the in-situ, learner-driven, collaborative learning experiences that characterize informal STEM pedagogies (Allen and Fraser, 2007; National Research Council, 2009).

Particularly in informal learning settings, such as home, after-school, and makerspace environments, the benefits of STEM engagement are often intangible and difficult to measure (Allen and Fraser, 2007; Cox, 2013; National Research Council, 2009). Consequently, despite the importance of social and emotional experiences in informal STEM education, there is limited empirical research about the impact of technology-rich learning environments on children's psychosocial development. This is especially concerning in early childhood (ages 4-8 years) where interdisciplinary and experiential STEM activities are pivotal to children's socioemotional growth, as children are already forming identities and potentially harmful stereotypes about STEM disciplines (Kuhn et al., 1978; Metz, 2007; Signorella et al., 1993; Steele, 1997; Sullivan, 2016). This paper seeks to address this gap in the literature, by investigating the positive character outcomes of Kindergarten children (aged 5-7 years) as they engaged in technology-enriched learning activities within an early childhood makerspace. The study uses the lens of Positive Technological Development (PTD), a pedagogical framework that describes developmentally appropriate experiences that young children can have when using technology (Bers, 2012).

In the following sections, we will summarize relevant research on STEM education in early childhood and the PTD framework. Following this, we describe the current study which examined one Kindergarten classroom of $n$ $=17$ students and $n=3$ teachers during their visits to an early childhood makerspace. Specifically, this study asks the following research questions: 1) How did Kindergarten children in a makerspace engage in the different kinds of behaviors described by Bers' (2012) PTD framework, and 2) Which elements of the learning environment specifically supported cbildren's PTD. Researchers measured the frequency of children's positive behaviors and interactions (such as collaboration and creativity) by using an evaluative tool rooted in the PTD framework. Results from these evaluations and ethnographic observations were analyzed to determine the PTD alignment of the children, teachers, and the physical space. Limitations of the current study and recommendations for future work will be discussed. The paper will conclude with a reflection about the impact of this work for the field of informal STEM education in the early childhood years.

\section{LITERATURE REVIEW}

In this section, we first summarize relevant research on informal STEM learning for supporting cognitive and psychosocial development in young children and discuss theoretical underpinnings for pursuing this work. We then describe the PTD framework for designing positive experiences with technology in early childhood to support children's interpersonal and intrapersonal development. Finally, we describe promising findings from research on PTD in a variety of learning settings and connect findings to the current research question on children's PTD in makerspaces.

\section{The Role of Technology in Young Children's Psychosocial Development}

Advancing STEM education, particularly the emergent sub-domain of technology, has grown into an international topic (Becker and Park, 2011; Bybee, 2010; Marginson et al., 2013). Education researchers argue persuasively that technological fluency and digital literacy are critical for children's 21st century readiness (Bellanca, 2010; Clements and Samara, 2003; Yelland, 2005). However, some worry that rapid innovation is outpacing our ability to understand the risks of these new technologies, and that children's technological fluency will come at the cost of their psychosocial development (the development of social patterns and individual thoughts and behaviors) (Alliance for Childhood, 2000; Armstrong and Casement, 2000; Turkle, 2016). In a survey of 3,377 US parents, participants reported that they are concerned with their children's technology use and that they actively seek ways to help children use digital media to support psychosocial development, particularly in areas of integrity and communication (Common Sense Media, 2017, p. 7).

Although these are valid concerns, empirical research shows that young children do engage in rich social experiences through digital media. This modern debate about the safety of computer technology echoes similar debates about television, radio, and films earlier in the $20^{\text {th }}$ century. As Wartella and Jennings (2000) point out, each wave of controversy and research surrounding new technology eventually found that technological experiences are not created equal, and children can gain social and cognitive advantages from quality interactive technologies. Research has shown that young children can make social, emotional, and cognitive developmental gains by engaging with certain computer technologies (Bers, 2012; Clements and Samara, 2003; Scardamalia and Bereiter, 1993; Sullivan and Bers, 2016; Yelland, 2005). Many studies involving screen-based technologies have 
shown the potential to enhance 4- and 5-year-old children's self-reflection, science inquiry, creativity, peer-to-peer socialization, and verbal conversation (Clements and Sarama, 2003; Flether-Flinn and Gravatt, 1995; Yelland, 2005). Bers suggests that the best way to foster these kinds of healthy experiences with technologies is to consider the context and purpose of technology exposure and connect to other domains and activities that are healthy for children (Bers, 2012). For example, screen-free coding tools like the KIBO robotics kit can engage children in physical coding activities that foster gross-motor coordination, and open-ended tools like the ScratchJr programming environment can present coding as an expressive medium to promote story-telling and artistic development (Bers, 2018; Pea and Kurland, 1984; Resnick, 2006; Wyeth, 2008).

Recently, work on educational technology has focused on informal learning environments as promising spaces for supporting learners' personal and social growth through novel STEM experiences (Honey and Kanter, 2013; Bers, Strawhacker, and Vizner, 2018; Syvertsen and Pigozzi, 2010). For example, makerspaces, often located in schools and libraries, are collaborative workspaces with a variety of novel and traditional building tools (e.g. 3D printers, laser cutters, woodworking equipment), that allow learners to work on personally meaningful projects within a community of peers and mentors (Honey and Kanter, 2013). Developmentally appropriate environments, collaborative technology arrangements, and support resources (e.g. staff people, reference materials) are all design elements of a learning space that can maximize children's positive interactions with novel digital tools (Antle and Wise, 2013; Bers, 2012; Bers et al., 2018; Syvertsen and Pigozzi, 2010). Makerspaces have been identified as community spaces that can support apprentice-mentor relationships, promote democratization of knowledge, and foster community engagement (Blikstein and Worsley, 2014; Kafai, Peppler, and Chapman, 2009; Rajala 2016; Sheridan et al., 2014). This is because makerspaces are designed to allow a variety of experimental and learnerdriven approaches to design-oriented tasks with novel tools, so they welcome a diversity of learning styles while also supporting conventional engineering and technologist practices (Kafai et al., 2009; Syvertsen and Pigozzi, 2010). This distributed expertise across all members of the group (rather than just one educator) can also address challenges of unconfident teachers who are uncertain about how to teach new technologies and skills (Bers et al., 2013; Litts, 2015). Learning theorists in the Vygotskian tradition would call makerspaces sites of sociocultural learning, since they foster a community of individuals with shared interests, whose relationships evolve over time as they each pursue diverse expertise (Cole, 1996; Lave and Wenger, 1991; Lemke, 2001; Leontiev, 1978; Vygotsky, 1963). In other words, makerspaces can support interpersonal and intrapersonal development, providing children opportunities to cultivate a strong personal identity through building, maintaining, and leading their community. In this study, we investigate the affordances of a makerspace for supporting children's psychosocial development and measure their developmental outcomes through the lens of the PTD framework, described in the next section.

\section{Positive Technological Development (PTD)}

Positive Technological Development is a framework to evaluate the learning that happens in informal learning environments, when children engage in digital experiences (Bers, 2012). PTD is rooted in Seymour Papert's pioneering work on Constructionism, a theoretical approach concerned with the unique meta-cognitive learning opportunities afforded by computer programming (Papert, 1980). Papert argued that when children code, they create digital "microworlds," or virtual spaces where they have programmed all the rules and behaviors in that world. When creating (and testing, and breaking) these programmatic rules, children can learn about how the real world works, and also about their own thinking processes (Papert, 1980). PTD also draws on research from the field of Positive Youth Development, which focuses on how to foster positive and pro-social developmental outcomes in children and young adults (Lerner et al., 2003). The purpose of the PTD framework is to apply development science to inform our understanding of how children can "use technology to make positive contributions to the development of self and of society" (Bers et al., 2009, pg. 22). In practice, PTD serves as a flexible, interventionist framework for educators to design and evaluate curriculum in a variety of early childhood settings to support children's positive engagement with digital experiences and for designers of technologies to develop positive technical affordances. In the current study, PTD was used to guide the design of the makerspace where the study took place (Bers et al., 2018) as well as the observational data collection measures. The six behaviors of the PTD framework, or the " 6 Cs" are the main constructs of interest (Bers, 2012). In the next section, each of these six aspects of PTD is described in detail.

PTD is evidenced by six positive behaviors that children exhibit when engaging in developmentally appropriate digital explorations (Bers, 2012). These include three intrapersonal skills of content creation, creativity, and choices of conduct, and three interpersonal skills of communication, collaboration, and community building (see Figure 1) (Bers et al., 2009). PTD behaviors are evidence that children are developing positive character assets and can be supported by technology-rich classroom activities.

Intrapersonal skills in PTD are related to a child's self-regulation and personal growth (Bers, 2012). By engaging deeply with expressive technologies and media, children can engage in rich personal exploration. Content creation is a child's ability to fluently use tools and materials to create new artifacts or meaningfully alter existing ones. This 


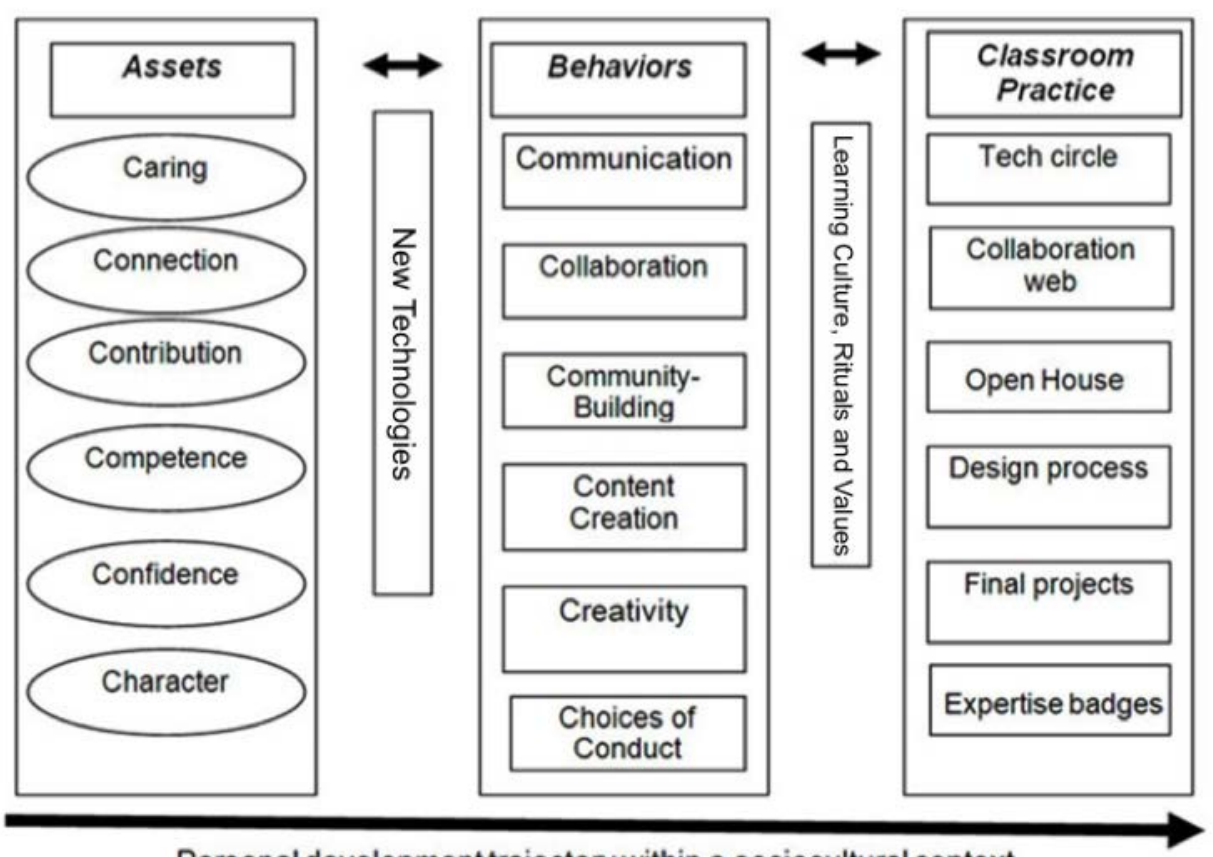

Personal development trajectory within a sociocultural context

Figure 1. The Positive Technological Development Framework. The PTD behaviors (center column) are rooted in character assets of Positive Youth Development (left) and can be supported by positive classroom practices with technologies (right) (reproduced with author permission from Bers, 2012)

skill is related closely to a child's sense of competence, or their ability to persevere towards their goals by engaging in a design process (Bers, 2012). Creativity refers to a child's flexibility, imagination, and interpretive skill. Creativity is evident when a child has confidence in her own ideas and believes that her perspective is worth expressing through her created work (Pugnali et al., 2017). Choices of conduct relate to a child's personal sense of morality, typically exhibited through their decision making. This skill is correlated with the development of character (Bers et al., 2009). Children who demonstrate strong and consistent choices of conduct often cultivate technological expertise and digital literacy through their dedication and hard work (Kazakoff, 2014).

The interpersonal skills relate to children's ability to cultivate relationships and emotional connection with others. PTD advocates for a technological landscape with diverse communication media (e.g. text, voice, image) specifically to help children forge positive connections with others. Communication refers to children's ability to share ideas and interpret the work of others and is connected to a child's sense of caring about people other than themselves. Collaboration extends shared ideas into shared action, through organized systems of coordinated design. The ability to collaborate is a key developmental milestone for young children and signifies their developing sense of mutual connection with others (Bers, 2012; Vygotsky, 1973). Finally, community building represents an integration of the other assets supported by PTD, as children can channel their personal and social skills to form caring networks of collaborators in both digital and physical spaces. Community building through technology might involve using technology to design a tool to help others, or creating and participating in a virtual community. Community building in PTD represents the child's ability to use design skills to contribute meaningfully towards the good of the community.

All of these skills combine to form children's holistic psychosocial development. The PTD framework is useful for effecting positive outcomes through technology (Bers, 2012). In the next section, we summarize research findings on the effectiveness of PTD as an interventionist framework.

\section{Prior Research with PTD}

Because it is an interventionist approach, the PTD framework has been applied to designing and evaluating curricula, environments, and technologies for children. The ScratchJr programming app (Flannery et al., 2013), the KIBO robotic kit (Sullivan et al., 2015), the ZORA Virtual World for medical communities (Bers and Cantrell, 2012), and several early childhood makerspaces (Bers et al., 2018) have all been designed with PTD constructs and recommendations in mind. It is important to consider the design of learning spaces, as spaces can impact children's learning in same way that teachers can (Bers et al., 2018; Brooks, 2011; Strong-Wilson and Ellis, 2007). Additionally, teachers face challenges of preparedness and lack of confidence when introducing new technologies (Banas, 2010; Bers et al., 2013; Mumtaz, 2000). Researchers have found that teachers can be wary of integrating new technologies 
into their practice and are sometimes not confident to try hands-on learning experiences with the tools themselves (Bers et al., 2013). In this study, we explore how a makerspace can support children's PTD engagement, even in ways that a teacher may not be able to.

Design elements of PTD-aligned tools and spaces include leveraging children's intuitive understanding and developing knowledge about the world, creating child-directed experiences, allowing children to learn about technology as they use it, and ensuring that the environment and context of the holistic education experience align with the goals of introducing the technology (Bers, 2012; Strawhacker et al., 2015). Tools should be responsive, with clear indicators of where to touch, and should offer creative opportunities to children to build digital artifacts of their own design (Bers, 2012). Environments should offer technologies at a child's eye-level, with room to play and space to work, and flexibility to let children shape the space to their own needs (Bers, Strawhacker, and Vizner, 2018). Tools designed with these features in mind show consistently high engagement and enthusiasm from child users (Bers and Cantrell, 2012; Bers et al., 2018; Flannery et al., 2013; Sullivan et al., 2015).

PTD is also used to evaluate learners' psychosocial outcomes. In an early study of PTD engagement in 186 adolescent youth, Bers et al. (2009) found high correlations between their PTD behaviors and students' fully developed character assets, confirming the relationship between PTD and psychosocial development. Bers et al. (2009) also recommended including ethnographic descriptions of children's behaviors, to contextualize general measures of PTD engagement. In another study researchers at a 1-week intensive summer technology workshop for young children investigated children's PTD engagement while one group used ScratchJr and another used the KIBO robot (Pugnali et al., 2017). Children demonstrated high overall engagement with PTD constructs, although ethnographic observations revealed qualitative differences in how children engaged in PTD (Pugnali et al., 2017). For example, both groups engaged in communication, but children working with the physical robotic kit were able to use visual cues (e.g. looking around the room) to get inspiration from friends or alert a teacher to off-task behavior, while children using the tablet-based ScratchJr were less likely to view each other's projects, and more likely to verbally communicate with friends for ideas or ask teachers for help.

Researchers have also explored PTD engagement in school settings. In five English-speaking schools in Singapore, 98 preschool children were assessed on their PTD engagement during a structured 7-week robotic intervention (Sullivan and Bers, 2017). Observational checklists called "PTD Checklists" were used to categorize children's behavior along 5-point Likert-style scales to determine how often they demonstrated PTD behaviors. On average, children showed high engagement in all areas of PTD except for community building and choices of conduct. The authors hypothesized that the high engagement with other aspects of PTD was related to the focus of the robotics curriculum on building and programming robotic technologies.

\section{Purpose of the Present Study}

In the current study, we depart from previous work on PTD by observing children in informal, open-ended play sessions in a makerspace rather than during structured curricular activities. The makerspace setting and technological tools available to children were all designed or selected to align with the PTD framework. The purpose of this study is to learn the affordances of the space and learning community for supporting PTD engagement. In order to capture children's PTD outcomes, we applied ethnographic methods for observing PTD (Bers et al., 2009; Sullivan et al., 2017), combined with a modified version of the PTD Checklists used by Sullivan and Bers (2017). This study addresses the following research questions:

1) How can Kindergarten children in a makerspace engage with the different aspects of Bers' (2012) PTD framework?

2) Which elements of the learning environment specifically supported children's PTD?

Question one pertains to group dynamics, and so children's behaviors were categorized with PTD checklists at the aggregate level. The average amount of PTD behaviors across all children comprised the PTD engagement of the group being observed. We hypothesized that children would engage equitably in all aspects of PTD, because the space was designed with all PTD aspects in mind. In order to address question two, the PTD checklist was modified to apply to teachers and the physical space, to capture the holistic learning environment. we hypothesized that the space would support all aspects of PTD because it was designed to align with the PTD framework, while educators might have different strengths across the aspects because people have diverse experiences that might not necessarily align with a learning framework like PTD. Further, we hypothesized that teachers would show lower engagement in aspects of creativity and content creation. This hypothesis is consistent with prior findings from teacher professional development research, which shows that teachers can be unconfident with novel technologies and hesitant to try new tools themselves (Ber et al., 2013). 


\section{METHOD}

\section{Participants}

$N=20$ participants ( $n=3$ teachers, $n=17$ children) from the Eliot-Pearson Children's School (EPCS) engaged in open-ended learning activities in the Early Childhood Makerspace at Eliot-Pearson. EPCS is a private, tuitionbased school in Medford, MA that offers needs-based aid to eligible families according to Massachusetts state guidelines. It is also a laboratory-demonstration school affiliated with the Eliot-Pearson Department of Child Study and Human Development at Tufts University. The Children's School enrolls approximately 80 children. It has preschool through second grade classes that vary in length and frequency. The school curriculum focuses on inclusion, and the administration has a stated mission of recruiting a diverse student body that is representative of the local neighborhood and context.

\section{Measures}

Data was collected using two (2) different 18-item observational instruments called PTD checklists (See Appendix A: PTD Engagement Checklists). These two checklists are designed to capture the participant behaviors and environmental affordances of an active learning environment and categorize findings into the 6 behaviors identified by the PTD framework. The checklists used in this study are based on existing checklists (Sullivan and Bers, 2017; Pugnali et al., 2017), but refined for clarity. Additionally, the "environment checklist" was developed to capture educator and learning space affordances, whereas previous checklists had only focused on children's behavior. All items were rated on a Likert-type scale ranging from 1 (never) to 5 (always), with "not applicable" available as an option for each item. Sample items on the children's checklist included "Children iterate on projects" (content creation) and "Children engage in conversation (verbally or non-verbally) with adults" (communication). Sample items on the environment and educator checklist included "There is evidence in the space of the local location or context" (community building) and "Facilitators engage children in non-judgmental conversation about choices" (choices of conduct). Two researchers observed each of the six total sessions during the 2-week data collection period. Each researcher collected two checklist observations per group visit: one checklist for children's behaviors, and the other for the learning environment and teacher. Twenty-four total checklists were collected, representing 6 hours of observations.

Researchers also collected data in the form of video footage of all makerspace interactions, with two cameras capturing opposite angles of activity in the space. To address the small sample and enrich the quality of conclusions drawn from the data, researchers transcribed and coded interactions from all three teachers and a random selection of six children to serve as single-case study subjects (Guest et al., 2011; Saldaña, 2015). These transcripts and videos were coded using confirmatory thematic analysis to identify and code patterns of actions and behaviors that children engaged in while using technology (Guest et al., 2011). These behaviors were categorized into the research constructs of the PTD framework, with a positive or negative valence to indicate when children were exhibiting pro- or anti-construct behaviors. For example, sharing with peers was a positive valence of collaboration, while withholding materials was a negative valence. Through this hypothesis-driven coding process, researchers arrived at several case stories to contextualize and describe findings from the quantitative PTD checklist observations.

\section{Addressing Bias}

This study is a sub-project of the Making Engineering Playful in Schools project, a collaboration between the Developmental Technologies Research Group at Tufts, the Center for Engineering Education and Outreach and Tufts, and the LEGO Foundation. The current protocol for this research has been ethically approved by the Tufts University Institutional Review Board (IRB). Consent forms to have their child's data and image used for research purposes were distributed to parents through outlets in their school community, with no consequences for parents who declined consent. Since the study was also providing an educational service for the host school, the principal granted consent as the curricular custodian to allow all Kindergarten children to participate in the makerspace intervention, even if data was not being collected on their progress. This was done to avoid the ethical issue of removing a child from an educational experience freely offered at the school.

\section{Procedure}

All data was collected within the Early Childhood Makerspace at Eliot-Pearson. Although children attended sessions during the school day, their visits in the makerspace were unstructured and more like free-play time. The makerspace was designed to support PTD behaviors through its space arrangement and the technologies offered (Bers et al., 2018). There are tools and materials for children to explore large-scale and small-scale building, robotics, programming, circuitry, simple machines, and traditional arts and crafts. Additionally, the furniture is modular and movable, so children can work sitting, lying, or standing up, and can even construct new furniture out of large building kits (see Figure 2). 


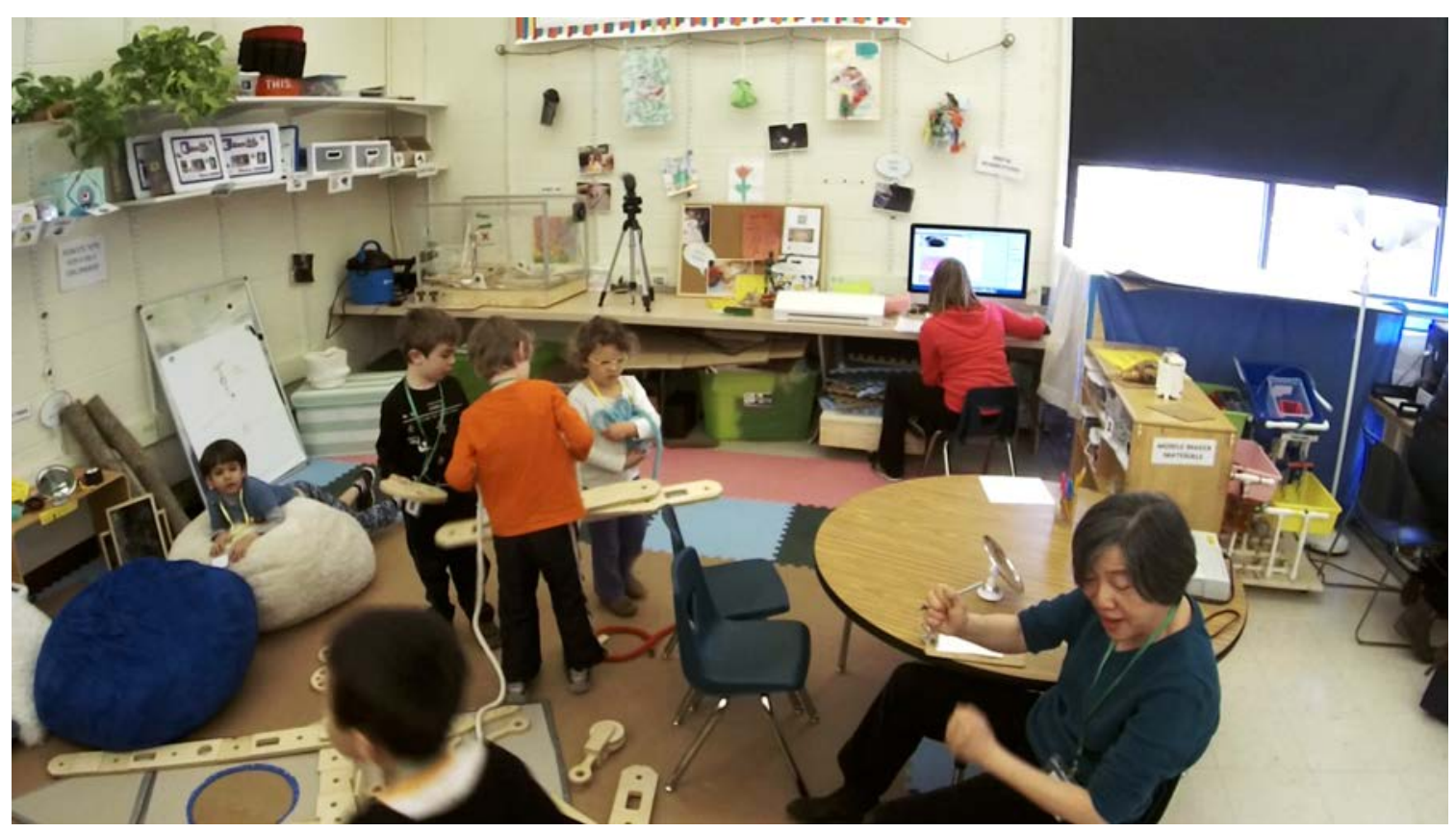

Figure 2. Children from the Eliot-Pearson Children's School engage in unstructured making at the Early Childhood Makerspace (Image reprinted with author permission from Bers et al., 2018)

The three Kindergarten teachers collaborated with researchers to plan makerspace sessions. At the teachers' recommendation, children came to the makerspace for weekly 60-minute sessions over the course of four weeks. This allowed children enough time to become deeply involved in personal making projects. Teachers recommended that children come in groups of about 5-6 so that they could engage in collaborative making experiences without being interrupted by chaotic group dynamics. They decided that each group should only come with one teacher at a time, to encourage child-directed activities. This resulted in three consistent groups (named 1,2 , and 3) that visited the space each week.

Three teachers participated in the current study. To clarify results, teachers will be referred to by the group of children that they worked with (e.g. teacher 1 worked with group 1). The teachers represented a diversity of teaching experience. Teacher 1 had over 20 years of experience working with early childhood, teacher 2 was in her first teaching year, and teacher 3 had four years of experience.

Although groups visited each week, data was only collected during the second and third weeks of makerspace visits. Researchers wanted to give children time to become accustomed to the space during the first visit, but also wanted to capture children as their making community was being formed before unseen social dynamics developed among the children and educators. The data collected represented a cross-sectional 2-week segment of each group's total makerspace activity.

\section{Analysis}

PTD Checklists were analyzed to determine children's PTD behaviors and the PTD affordances of the environment. Interrater agreement across the checklist items was sufficiently high (36 items; $\alpha=.67$ ) to evaluate average ratings. No items were marked "Not Observable," and there is no missing data. Due to the small sample size $(n=17)$ and the pilot-nature of the observational instruments used in this study, results were not analyzed using statistical tests. Instead, descriptive statistics were calculated from checklists. Scores from the PTD checklists were averaged and compared for trends, and compared with ethnographic observations to clarify findings.

\section{RESULTS}

In this section, statistics and trends from the PTD checklists are explored, and situated in the context of relevant observations. Researchers examined ethnographic field observations and videos of children's making activities to find examples of teachers and space supporting children's engagement in PTD behaviors. Illustrative vignettes are provided throughout to demonstrate children's activities. Results are presented in order of the research question they address. All names used are pseudonyms. 


\section{Children's Average PTD Behaviors}

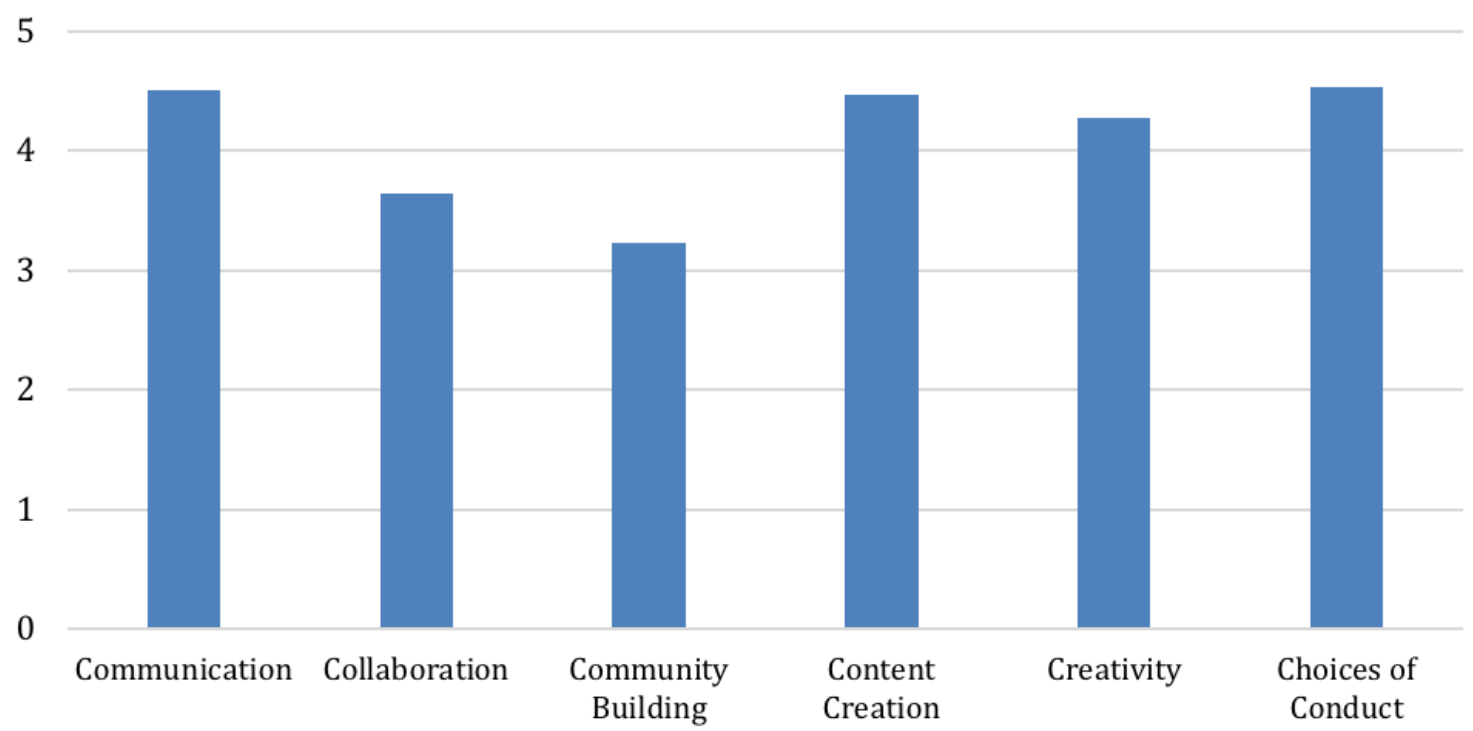

Figure 3. This chart displays the average number of times per sessions that each child displayed each of the "6 Cs" behaviors of PTD

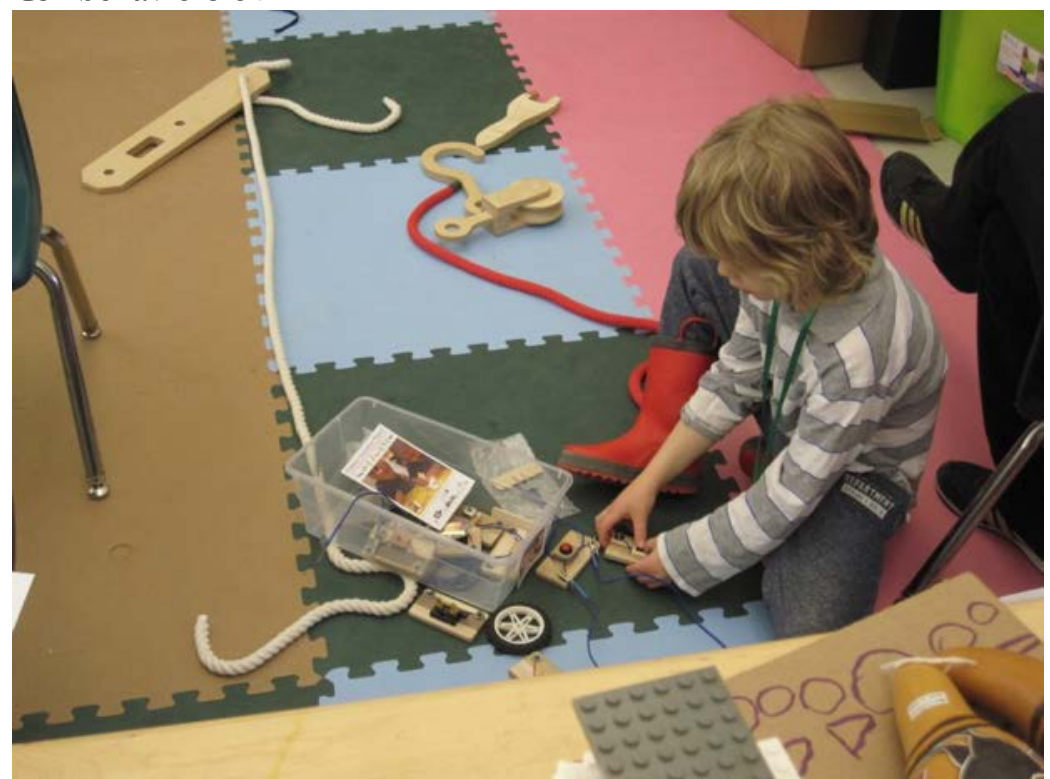

Figure 4. A child works with a circuit set to build a "light that will stay on even when my finger isn't pushing the button

\section{Children's PTD Engagement}

This section addresses the first research question, "How can Kindergarten children in a makerspace engage with the different behaviors identified by the PTD framework?" Scores from children's PTD checklists were averaged across all child participants (see Figure 3). Children earned a score between 4 and 5 on behaviors aligned with communication, content creation, creativity, and choices of conduct, meaning they exhibited those behaviors often (4) or always (5). Children showed collaboration and community building "Sometimes". None of the behaviors earned averages of 2 (almost never) or 1 (never).

Children demonstrated deep engagement with many of the aspects of PTD. The three vignettes below describe real examples of children engaging in collaboration, content creation, and choices of conduct in the makerspace.

Collaboration. Sonya asked her teacher for help because she wanted to make a wheelchair. Teacher 3 reminded her that Tony made car during their last visit, so she might ask him. Tony began to help Sonya, saying "you have to start with four wheels." She got to work, showing him her blocks and saying "I need four wheels. Is this four?" The boy held the wheels, saying "this is how it's supposed to be" and tried to connect them. When his construction fell over, he laughed and said "sometimes it doesn't go the way you want it, so you have to be flexible." He continued screwing and unscrewing wheels onto her construction while she tied a rope to one end of her 


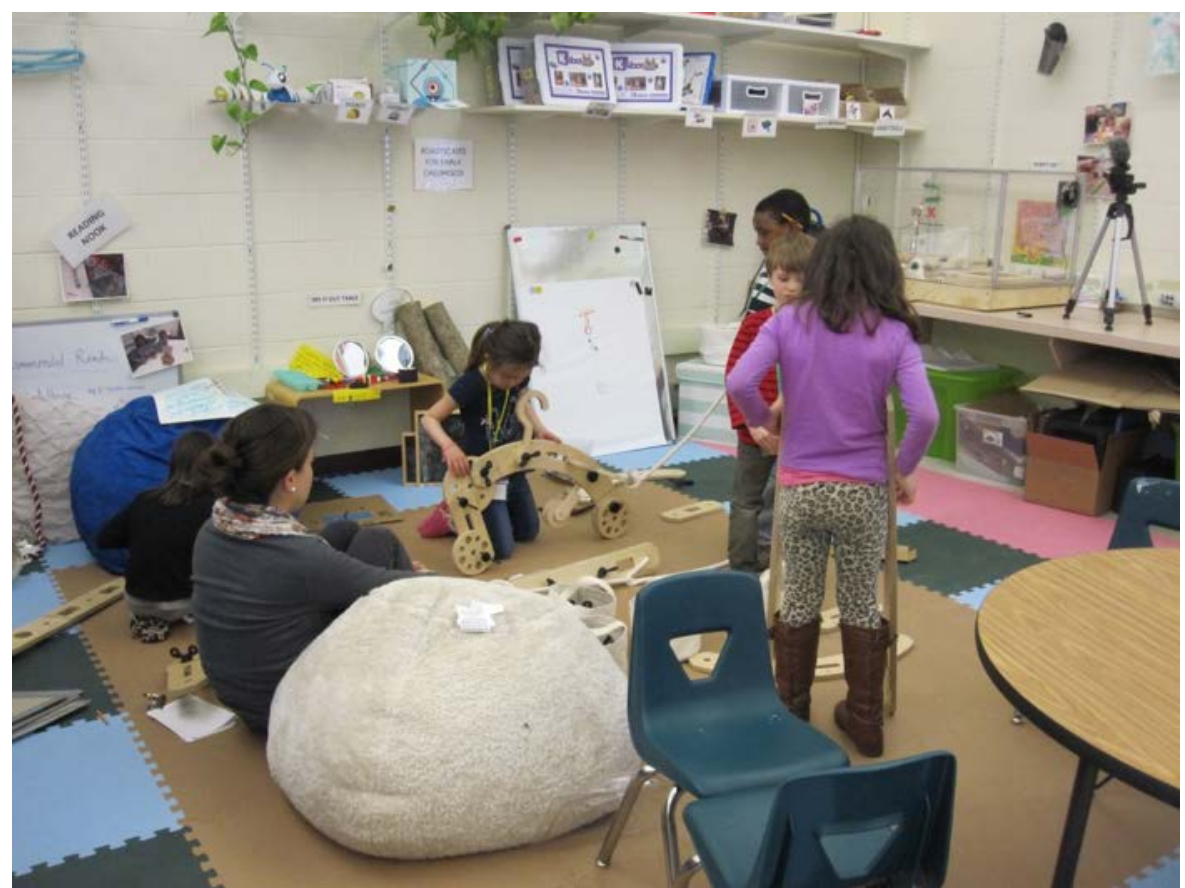

Figure 5. Children built constructions for injured or disabled people, including crutches (foreground right) and a pull-along wheelchair (background center), while Teacher 3 (left) observes

\section{Average Childrens Checklist Scores by Group}

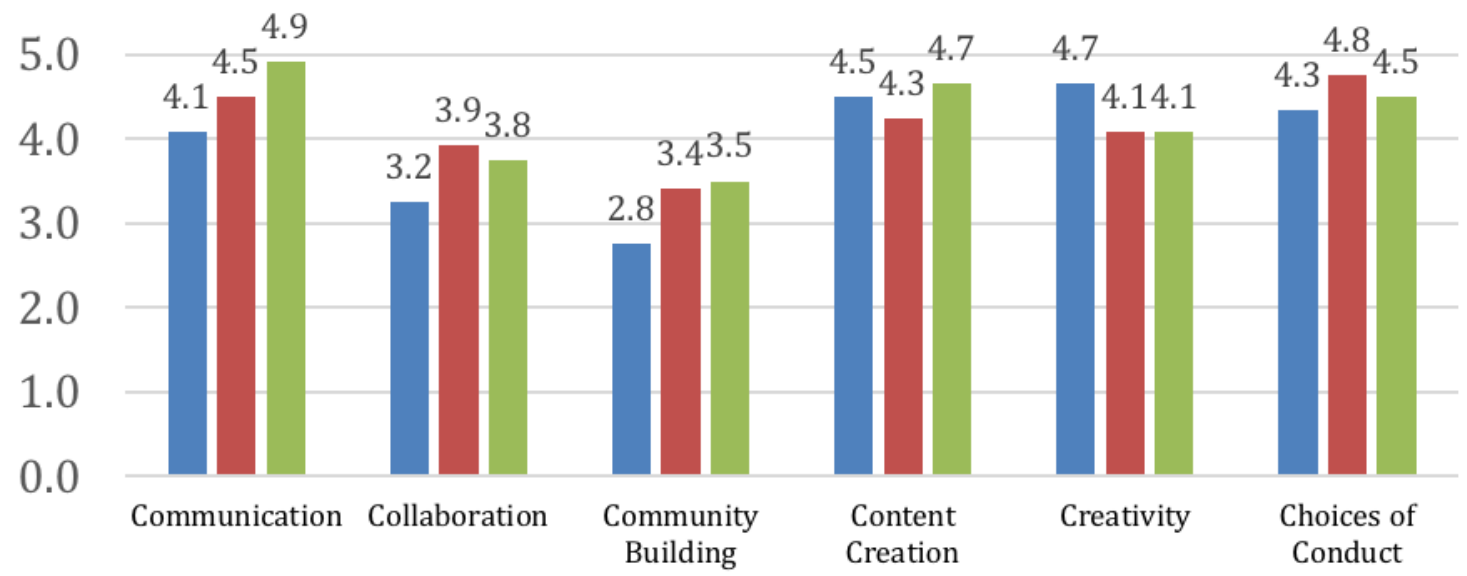

Figure 6. This chart displays the average number of times per session that separate. Group 1 is shown above in blue, group 2 is in red, and group 3 is in green

wheelchair, which she explained was there "so someone can pull it behind them." Tony and Sonya worked together toward a shared goal, to make a wheelchair, through their collaborative building.

Content Creation. A young boy named Leo became very interested in a small circuitry set (see Figure 4). He began to work alone on the kit, explaining that he loved electricity, and soon two friends were working with him. He often shouted exclamations like, "look what I made!" and "Yes! We did it!" When his teacher asked why he used a certain part in his circuit, he explained, "the switch is what I want, because then the light stays on even when my finger isn't pushing the button!" In this example, Leo was engaging deeply in content creation, as he built his circuit set to fit his goal.

Choices of Conduct. In group 3, Eloise was very curious about injuries, and frequently played make-believe games about medicine and healing. One day she decided to make crutches. Other children became curious about her crutches and after watching her work for a few minutes, another girl began to build a wheelchair (see Figure 5). While they worked, teacher 3 asked what they were building and Eloise replied, "engineers make things to help people so we are helping people also. People who can't walk might need this." Although she could have built anything, she chose to construct a helpful creation to solve a problem that someone else might have.

When it came to differences across children in separate groups, the average number of behaviors was only slightly diverse from the overall trend (see Figure 6). The similarities across groups are probably due to the fact 


\section{Overall PTD Support in Environment}

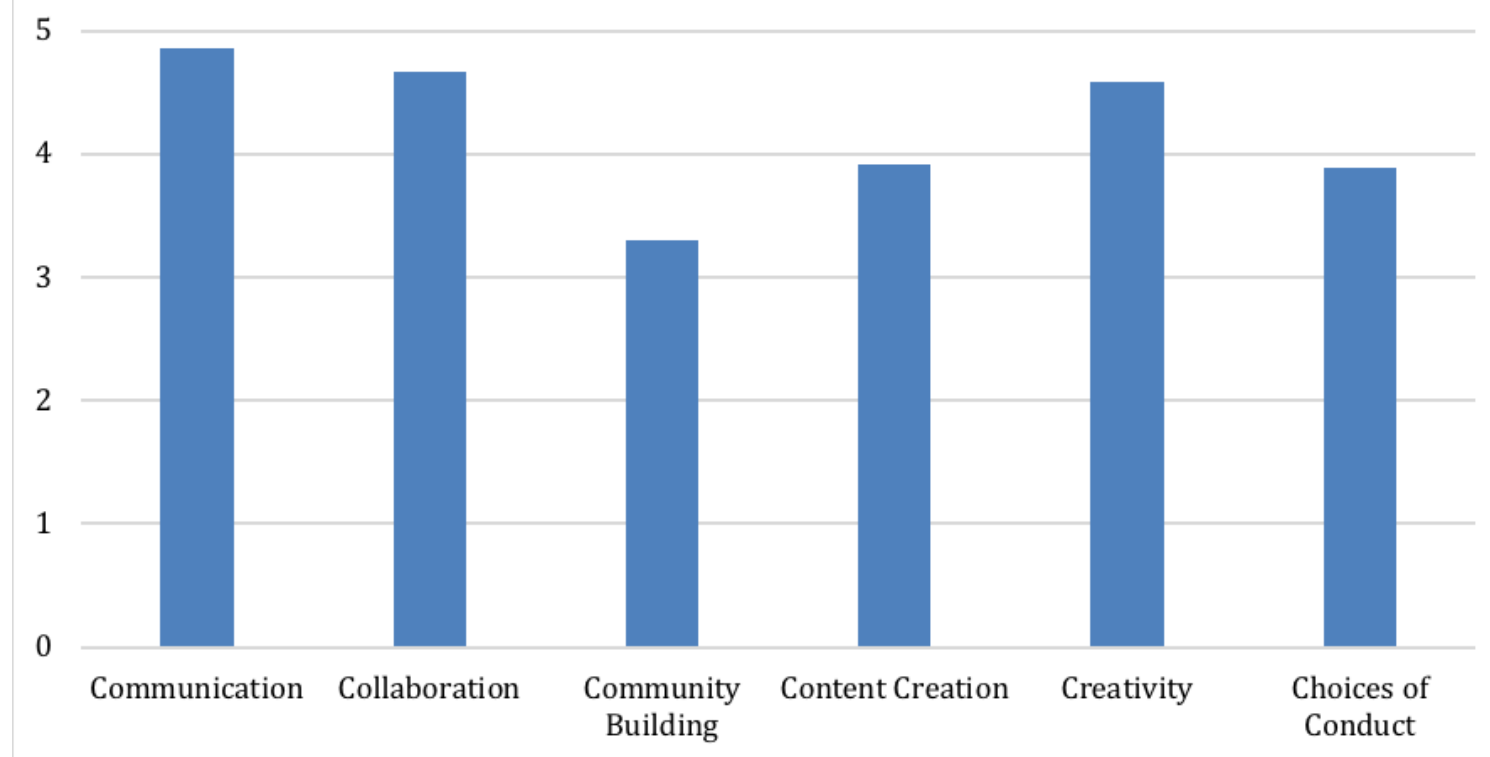

Figure 7. This chart displays the average amount of support for each of the "6 Cs" behaviors of PTD that the overall physical and teaching environment provided per session

that children all came from the same Kindergarten class and spent much of their time involved in the same instructional activities. However, there were slight differences. Group 1 showed relatively higher than average scores for creativity, but somewhat lower than average scores in all other PTD areas. This may seem surprising, since teacher 1 had much more teaching experience (over 20 years) than her teaching assistants. However, the trends in her children's behavior may be explained by the fact that she assigned herself the children who required the most specialized attention and were more demanding to work with than children in the other groups. Group 2 and group 3 were very similar in almost all behaviors, with group 3 scoring very slightly higher in communication and content creation. In general, these trends suggest that within each group, children followed the same overall trend of sometimes demonstrating collaboration and community building behaviors, and often (4) or always (5) showing the four other PTD behaviors. Although it is likely that children demonstrated similar trends because they came from the same classroom, the next section explores whether the learning environment and teachers could account for any of the variation in children's behaviors.

\section{Environmental PTD Affordances}

In this section, we turn to the second research question, "Which elements of the learning environment specifically supported children's PTD?" Scores for the amount of environmental PTD supports were averaged across all 6 sessions (see Figure 7). Observations from this checklist capture a combination of the physical environment (the room, the materials, the furniture) and the teaching environment (the teacher's behaviors and interactions with children). Overall, the physical and teaching environment always (5) or often (4) supported communication, collaboration, and creativity. Content creation and choices of conduct were often (4) or sometimes (3) supported, and community building was supported sometimes. None of the PTD aspects were "Never" or "Almost Never" supported.

The learning environment was instrumental in supporting children's PTD engagement. The three vignettes below describe real examples of teachers and the environment supporting children's communication, community building, and creativity in the makerspace.

Communication. During an early visit to the makerspace, teacher 1 prompted children to look around and record their observations before beginning to work (see Figure 8). She also remarked on their activity with comments like, "I see you are so excited about that funny robot. I wonder what you will make with it?" or "I want to know what's that in your hand. I see you are holding something, what will you make with it? What will it be?" Through her words, teacher 1 modeled for children how to observe and use descriptive words, and supported a plurality of expressive forms by allowing them to communicate their observations by speaking, writing, or drawing.

Community Building. During circle time at the end of one makerspace visit, teacher 1 asked to shake hands with girls Zoe and Hanna, saying "I want to congratulate your teamwork - so peaceful! Did you tell each other your ideas?" Zoe replied, "Yes, I said why don't we make a race car and she said why don't we make a house?" In this exchange, teacher 1 showed that in addition to the traditional teacher role of mediating social challenges, she 


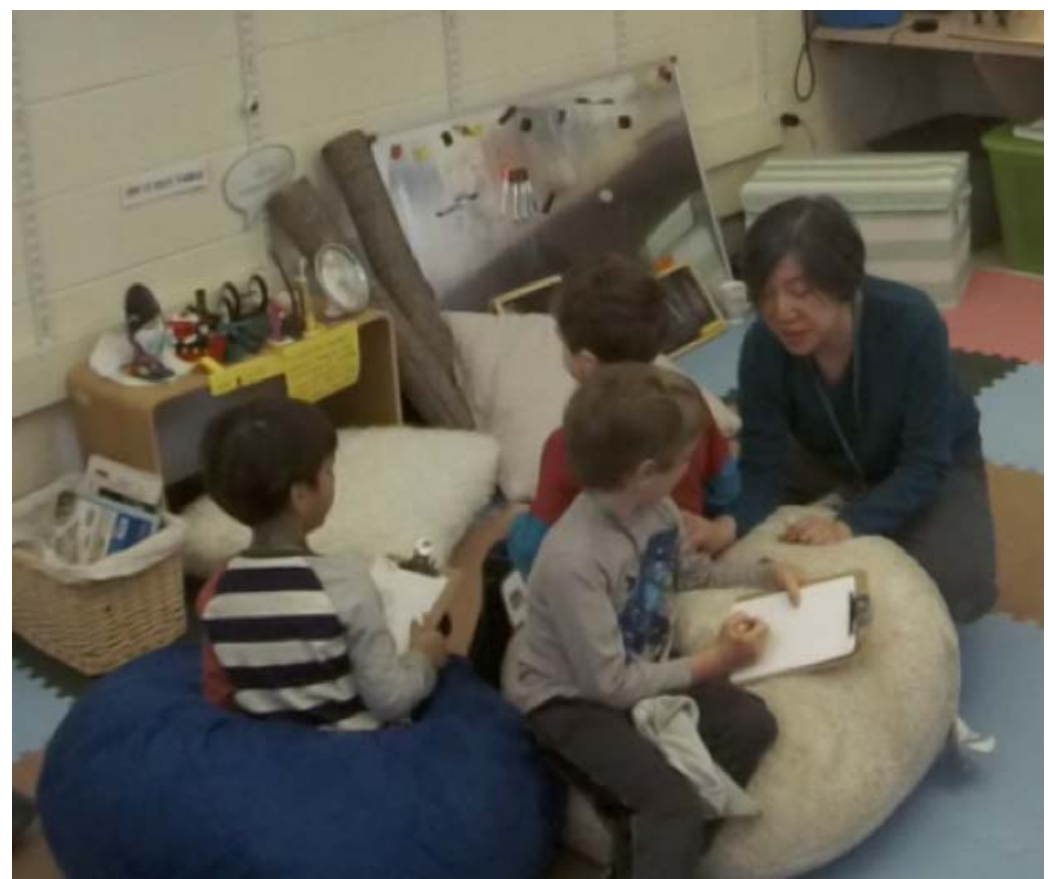

Figure 8. Teacher 1 asked children what they see and what they are drawing

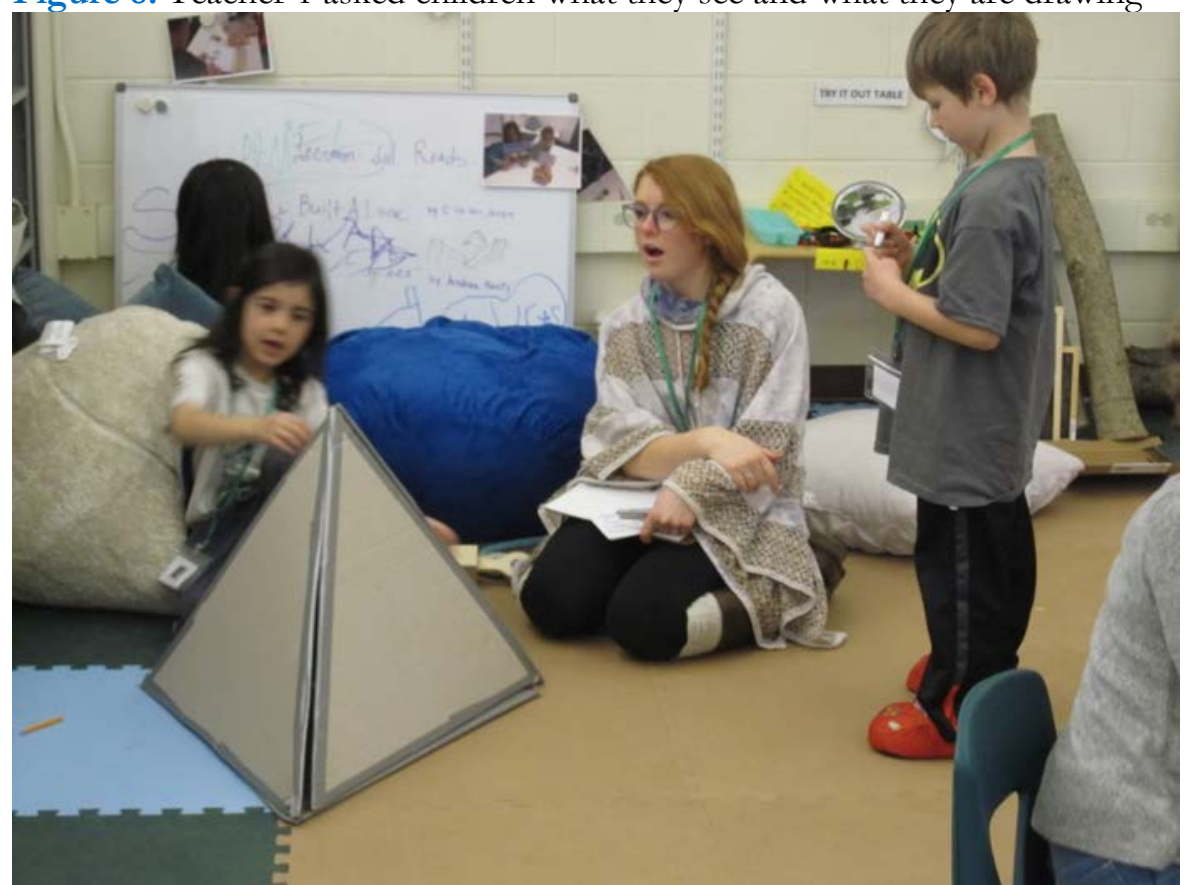

Figure 9. Teacher 2 listened enthusiastically and asked questions while a child explained his building design to her

also rewarded social successes. By waiting until circle time, she allowed the whole group to take part in this moment of social harmony and strengthened their shared community.

Creativity. Teacher 2 observed while Louis balanced two pieces of cardboard. After looking around, he used a piece of plastic to join the two pieces. He was about to take it apart when Teacher 2 said, "Louis I had no idea you could build like that! You are so creative; do you have a plan about what you're working on?" He considered his building, and then said "no, but it's going to be a house. Look what I'm going to do next" (see Figure 9).

Teacher 2 validated Louis's building endeavor and gave him the confidence to continue with his creative exploration.

Observations from this checklist capture a combination of the physical environment (the room, the materials, the furniture) and the teaching environment (the teacher's behaviors and interactions with children). In the next sections, PTD support scores for the physical and teaching environments will be explored separately.

When it came to teachers, all three showed high support for PTD behaviors (see Figure 10). Checklist scores revealed that all three teachers always (5) or often (4) supported all aspects of PTD, with the exception of content creation. All three teachers only sometimes supported this behavior. 


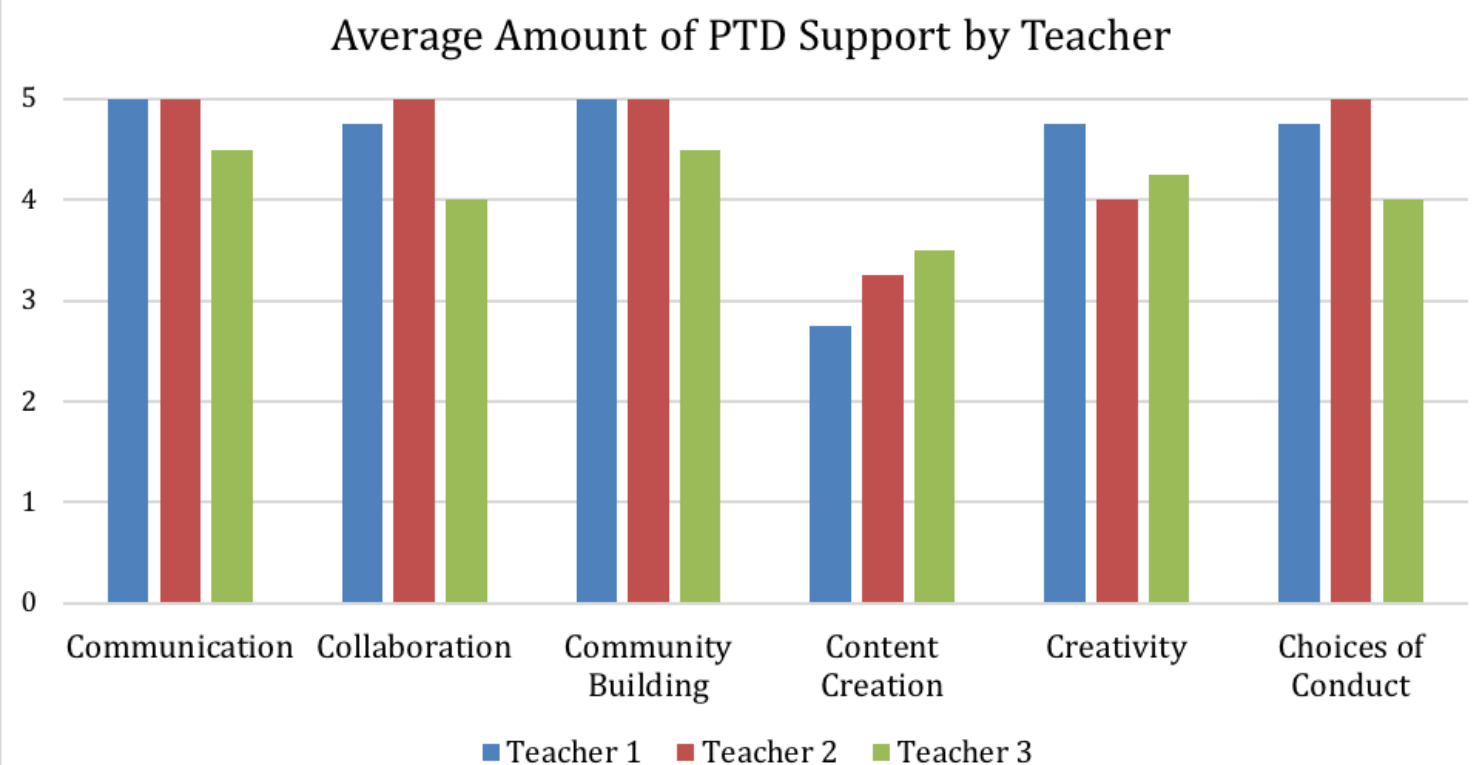

Figure 10. This chart displays the average amount of support for each of the "6 Cs" behaviors of PTD that each teacher provided per session

\section{Average Amount of PTD Support in Environment}

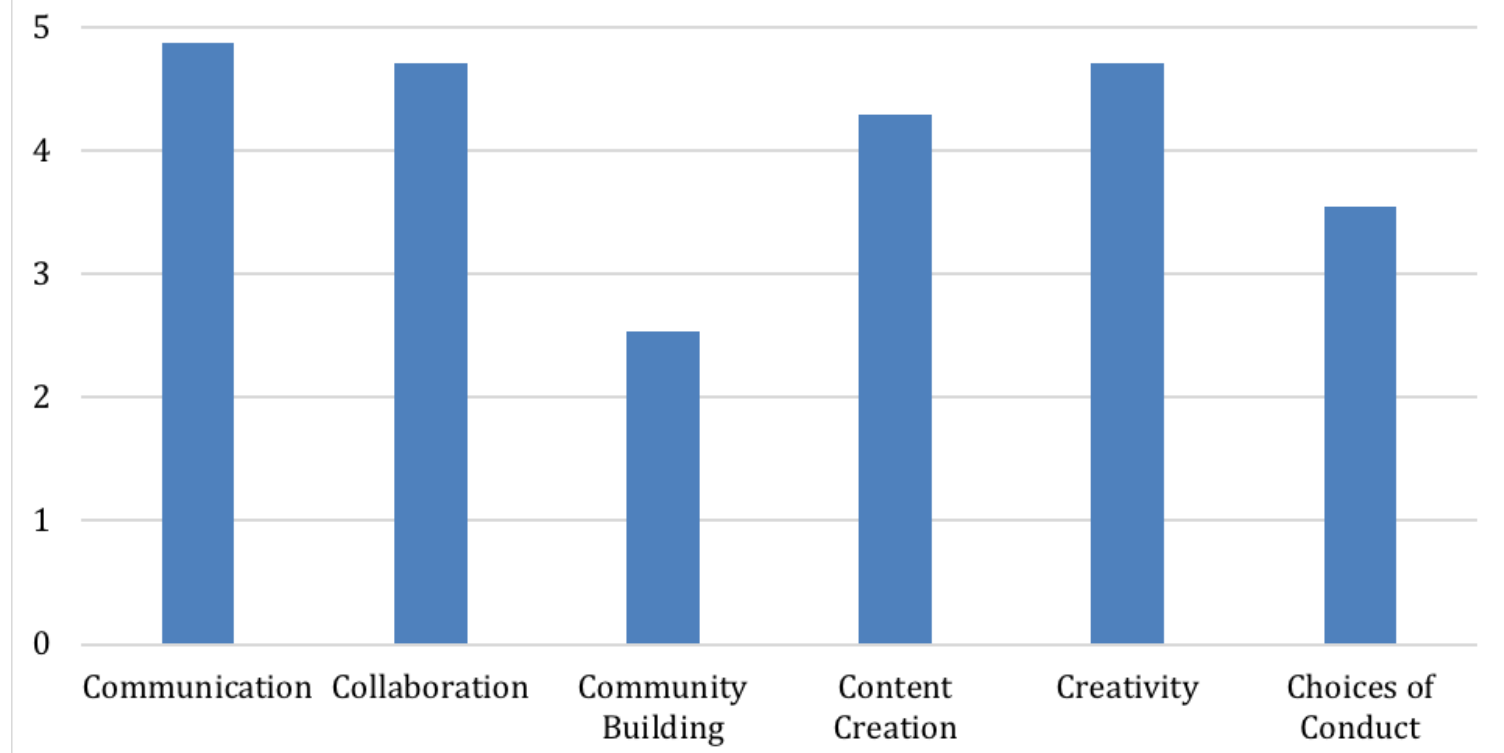

Figure 11. This chart displays the average amount of support for each of the " 6 Cs" behaviors of PTD that the physical environment offered

When it came to the physical environment, the space afforded many opportunities for PTD engagement (see Figure 11). The materials and furnishings often (4) or always (5) supported communication, collaboration, content creation, and creativity among children. The physical space sometimes (3) or often (4) supported children to make positive choices of conduct. The space was less supportive of community building behaviors, with communitybuilding décor and materials evident only sometimes (3) or almost never (2).

\section{Overall PTD Engagement}

Taken together, the findings reflect a few overall trends. Figure 12 shows a visual representation of the relationships among the environment, the teachers, and the children across each aspect of PTD. In general, there was moderate-to-high PTD support in the environment and from teachers, which corresponded with moderateto-high PTD engagement from children. Specifically, Teachers (represented in red) showed the highest support for choices of conduct and community building, over and above what the environment supported. The environment (shown in green) afforded the most opportunities for creativity and content creation, even beyond teacher support. Finally, although children (shown in blue) experienced high support for all aspects of PTD from 
Overall Evidence of PTD across Children, Teachers, and Environment

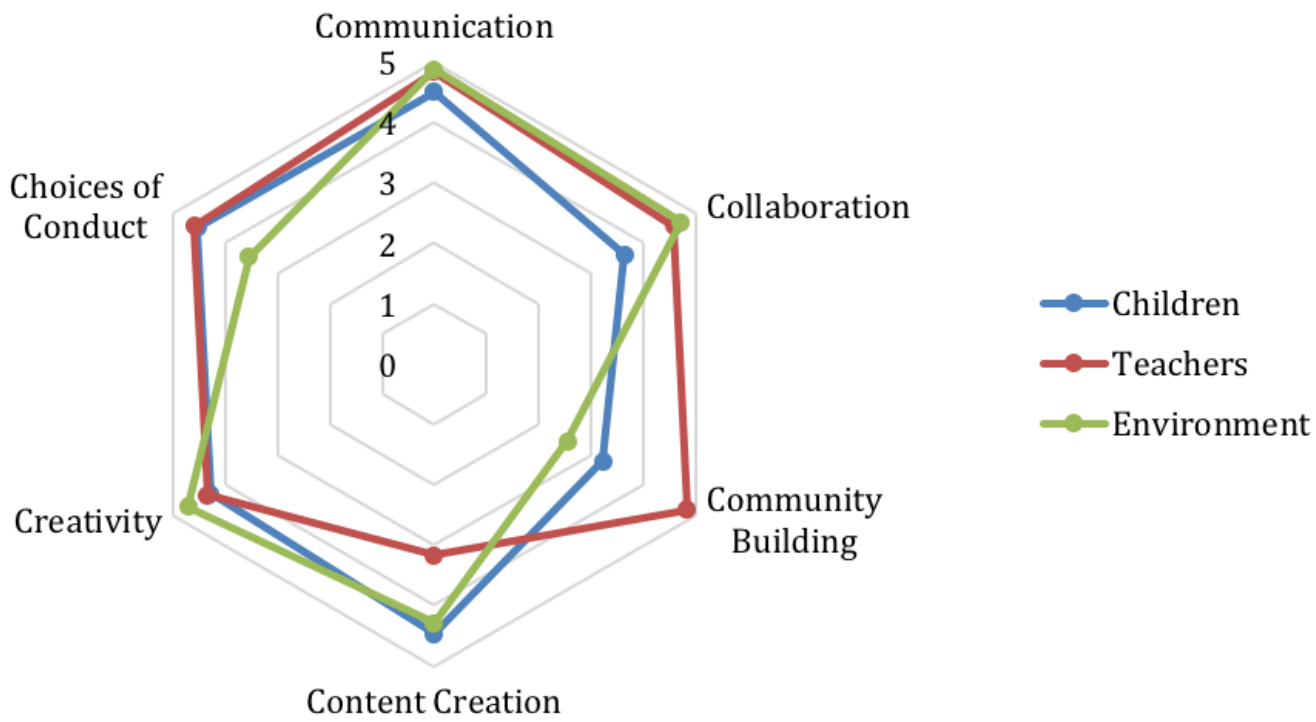

Figure 12. This chart represents relationships among children, teachers, and the environment across all dimentions of PTD

either teachers, the environment, or both, children still showed somewhat less evidence of collaboration and community building compared to other behaviors. In the next section, we explore possible explanations for these relationships.

\section{DISCUSSION}

\section{Summary of Findings}

In this study, we sought to address findings related to the following research questions:

1) How can Kindergarten children in a makerspace engage with the different aspects of Bers' (2012) PTD framework?

2) Which elements of the learning environment specifically supported children's PTD?

Regarding question 1, we hypothesized that children would engage in all aspects of PTD equally. In fact, we found that children engaged in most PTD aspects, but showed somewhat less evidence of collaboration and community building. For question 2, we hypothesized that the space would support all aspects of PTD. Contrary to our hypothesis, the space demonstrated support in most areas except for community building. We hypothesized that educators might show diverse levels of support for different aspects of PTD, but in fact all three educators supported the different aspects of PTD in similar amounts to each other. Finally, we hypothesized that teachers would show lower support of creativity and content creation, based on prior research that teachers can be unconfident and hesitant when using new technologies (Bers et al., 2013). Although all three teachers showed relatively low support for content creation, they were highly supportive of children's creativity. We've synthesized these findings into three core findings:

1) Children's creativity and content creation can be best supported by offering a unique and technology-rich learning environment. Results show that teachers and the environment offered plenty of opportunities for PTD engagement across most constructs, although they did not always overlap in their areas of high support. For example, the environment was more supportive of content creation and creativity than teachers were. This makes sense, since one would expect the tools and materials in the room to inspire children to build, program, and create. Still, children were able to demonstrate high engagement with most of these constructs. This finding is heartening in light of the challenges of technology integration facing teachers, because even teachers who are nervous about using technology can offer an environment that supports children in their 
digital creation. Additionally, this finding offers support to the claim made earlier in this paper, that a welldesigned space can offer learning supports that supplement and complement what teachers can offer.

2) Children's community building and choices of conduct can be best supported by caring and responsive teachers.

As mentioned in the previous proposal, teachers and the physical environment can successfully support children's PTD engagement in complementary ways. In this sample, teachers were more supportive than the space when it came to choices of conduct and community building. This is logical because teachers are human supports, so they are naturally better able to support social and moral development. This proposal is the complement of the above point, which is that in some areas, a good teacher can provide learning supports even when they are absent in the environment.

3) Even with bighly supportive teachers and physical environments, children may not be developmentally ready to engage in all aspects of PTD behaviors.

In general, students showed high PTD engagement when both teachers and the environment supported that behavior, but not always. For example, despite strong support from teachers and the environment, children were not often observed in spontaneous collaboration. Further, those children who did regularly collaborate were often older or more socially developed than their more individualistic peers. We suggest that this finding does not reveal a problem, but instead shows the natural diversity of developmental levels in any early childhood class. Children's individual developmental rhythms are highly variable (Phillips and Shonkoff, 2000). From a developmental perspective, it makes sense that Positive Technological Development is also highly individual and diverse among students. In this study, most students were somewhat less inclined to collaboration, meaning that perhaps this aspect of PTD requires more social development than the typical Kindergartener possesses. As children become ready to explore this out-ofreach skill, a strong support system of educators and environment are the best preparation to help them grow (Vygotsky, 1963).

These findings are all supported by the overall trends represented in Figure 12. Recall that the environment and the teachers showed slight variation how they supported PTD, and that children demonstrated yet a third pattern of PTD engagement. The overlapping points on that chart suggest that in some cases, it can be enough for only one element of the learning context to support children's PTD engagement. For example, children's engagement with content creation matched the environmental support for that aspect, and the opposite was true for choices of conduct, where child behaviors were more closely aligned with the amount of teacher support. In contrast, children's engagement with community building was somewhere between the amount of support from the environment and the teachers, indicating that children may need more support in this aspect than others. Finally, despite high support for collaboration from teachers and the learning environment, children still showed slightly less engagement, suggesting that children are still developing readiness for this aspect. These findings shed light on the nuanced and complex relationship among children and the many aspects of their learning context. Practitioners and researchers alike can use the results presented here align technology-rich learning experiences with the PTD framework to best support children's psychosocial development.

\section{LIMITATIONS AND FUTURE WORK}

The primary limitation of this study is the sample size. With a sample of $n=17$ children and $n=3$ teachers, it was not possible to conduct statistical analyses on the quantitative checklist data. Conducting this study with a larger sample could shed light on the statistical viability and replicability of the trends observed in this pilot work. However, the small sample also allowed for rich ethnographic observations to contextualize findings, offering credibility to findings from a qualitative perspective.

The PTD checklist instruments used in this study were based on prior research, but heavily adapted for the current study, and this was the first implementation of the environment checklist. Future work should explore this pilot instrument and validate it for research purposes. Despite this limitation, findings from the checklist correspond with qualitative observations. Although it is not validated for research use yet, it is a useful tool for practice-based settings, such as classrooms and makerspaces. Currently, there are few practical tools for evaluating the developmental appropriateness of digitally-enriched or traditional learning settings (Kuh et al., 2013; Olds, 2001). These checklists may be useful for educators and curriculum developers who hope to determine the PTDalignment of their teachers and learning space.

Additionally, researchers might want to articulate broadly-applicable recommendations for designing spaces to support each of the 6 Cs of the PTD framework. Currently, these recommendations exist for designing tools and lesson activities. Given the findings in this study about the importance of space in shaping the learning experience. Specific strategies should be developed to guide the development of learning spaces, particularly informal spaces where there are relatively fewer policy-level standards and recommendations to look to for best practices. 
Finally, future work could apply this study method to a variety of learning settings. The current setting was designed with PTD in mind, but the vast majority of learning spaces (especially in public schools) are not. Many informal afterschool clubs and extracurricular activities are held in whatever space is available, even in janitor's closets and auditoriums. In order to determine the impact of space on learning, it would be beneficial to compare results from these kinds of spaces, to determine how best to overcome deficits in the learning environment and still support children's PTD engagement.

\section{CONCLUSION}

As demonstrated through this ethnographic study of an informal early childhood makerspace, the learning environment plays a critical role in supporting children's positive technological development. Children in this study demonstrated high engagement across PTD behaviors, with somewhat lower evidence of collaboration. Teachers and the physical learning environment worked in complementary ways to support children's PTD engagement, overlapping in key areas of communication and collaboration. Teachers showed better ability to support social aspects of PTD, and the environment was better able to support content creation and creativity. Kindergarten children are experiencing transitional stages of development. Still, teachers in this study clearly felt that it was important to "stack the odds" by proving the best possible opportunities to engage in positive growth behaviors. It makes sense that children's learning environments, too, should be equally intentional and supportive of children's developing skills.

As new technologies and learning approaches develop and schools and informal spaces seek to keep pace with the future of education, it is important to remember the human element of learning. Digital experiences need to support children in character, moral, social, and emotional growth as well as cognitive learning experiences. Tools that narrowly support one domain or skill (sometimes called "drill and repeat" or "edutainment" tools) can lead educators to distrust new learning technologies (Banas, 2010; Bers et al., 2013; Mumtaz, 2000). However, the tenets of Positive Technological Development remind us that we do not need to choose between healthy development and technology-rich learning. Instead, it is up to researchers, policy makers, and practitioners to make choices that forefront developmentally appropriate tools and spaces, so that children reach their developmental needs by using technology and not by avoiding it. Actions like observing children while they use technology to understand their PTD engagement and designing technology-rich spaces and teaching interventions to fit the PTD framework, are the first steps to ensuring that children are engaging in positive development through technology.

\section{REFERENCES}

Allen, D. and Fraser, B. J. (2007). Parent and student perceptions of classroom learning environment and its association with student outcomes. Learning Environments Research, 10(1), 67-82. https://doi.org/10.1007/s10984-007-9018-z

Alliance for childhood. (2000). Fool's gold: A critical look at computers in childhood. Alliance for Childhood. Available at: www.allianceforchildhood.org (Accessed 28 February 2018)

Antle, A. N. and Wise, A. F. (2013). Getting down to details: Using theories of cognition and learning to inform tangible user interface design. Interacting with Computers, 25(1), 1-20. https:// doi.org/10.1093/iwc/iws007

Armstrong, A. and Casement, C. (2000). The child and the machine: How computers put our children's education at risk. Beltsville, MD: Robins Lane Press.

Banas, J. R. (2010). Teachers' attitudes toward technology: Considerations for designing preservice and practicing teacher instruction. Community \& Junior College Libraries, 16(2), 114-127. https://doi.org/10.1080/02763911003707552

Becker, K. and Park, K. (2011). Effects of integrative approaches among science, technology, engineering, and mathematics (STEM) subjects on students' learning: A preliminary meta-analysis. Journal of STEM Education: Innovations and Research, 12(5/6), 23.

Bellanca, J. A. (Ed.). (2010). 21st century skills: Rethinking how students learn. Solution Tree Press.

Bers, M. U. (2012). Designing Digital Experiences for Positive Youth Development: From Playpen to Playground, Oxford, Cary, NC.

Bers, M. U. (2018). Coding as a Playground: Programming and Computational Thinking in the Early Childhood Classroom. New York, NY: Routledge press.

Bers, M. U. and Cantrell, K. (2012). Virtual worlds for children with medical conditions: Experiences for promoting positive youth development. In Å. Smedberg (Ed.), E-health communities and online self-belp groups: Applications and usage (1-23). Hershey, PA: Medical Information Science Reference. 
Bers, M., Lynch, A. D. and Chau, C. (2009). Positive technological development: The multifaceted nature of youth technology use towards improving self and society. In Ching, C.C. \& Foley, B. J. (Eds.) Technology, Learning, and Identity: Research on the Development and Exploration of Selves in a Digital World. Cambridge University Press.

Bers, M. U., Seddighin, S. and Sullivan, A. (2013). Ready for robotics: Bringing together the T and E of STEM in early childhood teacher education. Journal of Technology and Teacher Education, 21 (3), 355-377.

Bers, M. U., Strawhacker, A. L. and Vizner, M. (2018). The design of early childhood makerspaces to support Positive Technological Development: Two case studies. Library Hi Tech. Advance Online Publication. https://doi.org/10.1108/LHT-06-2017-0112

Blikstein, P. and Worsley, M. (2014). Children Are Not Hackers. 2016). In Peppler, K., Halverson, E. and Kafai, Y. B. (Eds.) Makeology: Makerspaces as learning environments, 1.

Breiner, J. M., Harkness, S. S., Johnson, C. C. and Koehler, C. M. (2012). What is STEM? A discussion about conceptions of STEM in education and partnerships. School Science and Mathematics, 112(1), 3-11. https://doi.org/10.1111/j.1949-8594.2011.00109.x

Brooks, D. C. (2011). Space matters: The impact of formal learning environments on student learning. British Journal of Educational Technology, 42(5), 719-726. https://doi.org/10.1111/j.1467-8535.2010.01098.x

Burke, J. J. (2014). Makerspaces: A Practical Guide for Librarians, Vol. 8, Rowman \& Littlefield, Lanham, MD.

Bybee, R. W. (2010). Advancing STEM education: A 2020 vision. Tecbnology and Engineering Teacher, 70(1), 30-35.

Bybee, R. W. (2000). Achieving Technological Literacy: A National Imperative. Technology Teacher, 60(1), 23-28.

Chang, S., Keune, A., Peppler, K. and Regalla, L. (2015). Open portfolio project research brief series. Maker Education Initiative, Palo Alto, CA. Available at: https://makered.org/wp-content/uploads/2015/03/OpenPortfolio-Project-Research-Brief-Series_FULL_final-small.pdf

Clements, D. H. and Sarama, J. (2003). Strip mining for gold: Research and policy in educational technology-A response to "Fool's Gold". AACE Journal, 11(1), 7-69.

Cole, M. (1996). Cultural psychology. Cambridge, MA: Harvard University Press.

Cox, M. J. (2013). Formal to informal learning with IT: research challenges and issues for e-learning. Journal of computer assisted learning, 29(1), 85-105. https:// doi.org/10.1111/j.1365-2729.2012.00483.x

Common Sense Media. (2017). Character is Common Sense: A report on an initiative linking media, kids, and character strengths. San Francisco, CA. Common Sense Media.

Dakers, J. (Ed.). (2006). Defining technological literacy: Towards an epistemological framework. Springer. https://doi.org/10.1057/9781403983053

Flannery, L. P., Kazakoff, E. R., Bontá, P., Silverman, B., Bers, M. U. and Resnick, M. (2013). Designing ScratchJr: Support for early childhood learning through computer programming. In Proceedings of the 12th International Conference on Interaction Design and Children (IDC 113). ACM, New York, NY, USA, 1-10. https://doi.org/10.1145/2485760.2485785

Guest, G., MacQueen, K. M. and Namey, E. E. (2011). Applied thematic analysis. Sage.

Hollandsworth, R., Dowdy, L. and Donovan, J. (2011). Digital citizenship in K-12: It takes a village. TechTrends, 55(4), 37-47. https://doi.org/10.1007/s11528-011-0510-z

Honey, M. and Kanter, D. E. (Eds.). (2013). Design, make, play: Growing the next generation of STEM innovators. Routledge.

Kafai, Y. B., Peppler, K. A. and Chapman, R. N. (2009). The Computer Clubhouse: Constructionism and Creativity in Youth Communities. Technology, Education-Connections. Teachers College Press. 1234 Amsterdam Avenue, New York, NY 10027.

Kazakoff, E. R. (2014). Toward a theory-predicated definition of digital literacy for early childhood. Journal of Youth Development, 9(1), 41-58. https://doi.org/10.5195/JYD.2014.71

Kuh, L. P., Ponte, I. and Chau, C. (2013). The Impact of a Natural Playscape Installation on Young Children's Play Behaviors. Children Youth and Environments, 23(2), 49-77. https://doi.org/10.7721/chilyoutenvi.23.2.0049

Kuhn, D., Nash, S. C. and Brucken, L. (1978). Sex role concepts of two- and three-year-olds. Child Development, 49, 445-51. https:// doi.org/10.2307/1128709

Lave, J. and Wenger, E. (1991). Situated learning: Legitimate peripheral participation. Cambridge university press. https://doi.org/10.1017/CBO9780511815355

Litts, B. K. (2015, June). Resources, facilitation, and partnerships: three design considerations for youth makerspaces. In Proceedings of the 14th International Conference on Interaction Design and Children (pp. 347-350). ACM. https://doi.org/10.1145/2771839.2771913

Lemke, J. L. (2001). Articulating communities: Sociocultural perspectives on science education. Journal of research in science teaching, 38(3), 296-316. https://doi.org/10.1002/1098-2736(200103)38:3<296::AIDTEA1007>3.0.CO;2-R

Leontiev, A. N. (1978). Activity, consciousness, and personality. Englewood Cliffs, NJ: Prentice-Hall. 
Lerner, R. M., Dowling, E. M. and Anderson, P. M. (2003). Positive youth development: Thriving as the basis of personhood and civil society. Applied Developmental Science, 7(3), 172-180. https://doi.org/10.1207/S1532480XADS0703_8

Marginson, S., Tytler, R., Freeman, B. and Roberts, K. (2013). STEM: country comparisons: international comparisons of science, technology, engineering and mathematics (STEM) education. Final report. Australian Council of Learned Academies, Melbourne, Vic.

Metz, S. S. (2007). Attracting the engineering of 2020 today. In R. Burke and M. Mattis (Eds.) Women and Minorities in Science, Technology, Engineering and Mathematics: Upping the Numbers (pp. 184-209). Northampton, MA: Edward Elgar Publishing.

Minner, D., Erickson, E., Wu, S. and Martinez, A. (2012). Compendium of research instruments for STEM education. Part 2: Measuring students' content knowledge, reasoning skills, and psychological attributes. Cambridge, MA: Abt Associates. (Accessed 27 July, 2014).

Mumtaz, S. (2000). Factors affecting teachers' use of information and communications technology: a review of the literature. Journal of information technology for teacher education, 9(3), 319-342. https://doi.org/10.1080/14759390000200096

National Research Council. (2009). Learning science in informal environments: People, places, and pursuits. National Academies Press.

National Research Council. (2013). Education for life and work: Developing transferable knowledge and skills in the 21st century. National Academies Press.

Olds, A. R. (2001). Child Care Design Guide. McGraw-Hill, Blacklick, OH.

Pea, R. D. and Kurland, D. M. (1984). On the cognitive effects of learning computer programming. New Ideas in Psychology, 2, 137-168. https://doi.org/10.1016/0732-118X(84)90018-7

Phillips, D. A. and Shonkoff, J. P. (Eds.). (2000). From neurons to neighborhoods: The science of early childhood development. National Academies Press.

Pugnali, A., Sullivan, A. and Bers, M. U. (2017) The Impact of User Interface on Young Children's Computational Thinking. Journal of Information Technology Education: Innovations in Practice, 16, 172-193. https://doi.org/10.28945/3768

Rajala, A. (2016) Learning-by-Making and Educational Equity: STEM Learning and Identity Development in a School-Based Makerspace. Transforming Learning, Empowering Learners.

Resnick, M. (2006). Computer as paintbrush: Technology, play, and the creative society. In Singer, D., Golikoff, R., and Hirsh-Pasek, K. (eds.), Play = Learning: How play motivates and enhances children's cognitive and social-emotional growth. Oxford University Press. https://doi.org/10.1093/acprof:oso/9780195304381.003.0010

Ribble, M. (2015). Digital citizenship in schools: Nine elements all students should know. International Society for Technology in Education.

Robins, A., Rountree, J. and Rountree, N. (2003). Learning and Teaching Programming: A Review and Discussion. Computer Science Education, 13(2), 137-172. https://doi.org/10.1076/csed.13.2.137.14200

Saldaña, J. (2015). The coding manual for qualitative researchers. Sage.

Scardamalia, M. and Bereiter, C. (1993). Technologies for knowledge building discourse. Communications of the ACM, 36, 37-41. https://doi.org/10.1145/155049.155056

Sheridan, K., Halverson, E. R., Litts, B., Brahms, L., Jacobs-Priebe, L. and Owens, T. (2014). Learning in the making: A comparative case study of three makerspaces. Harvard Educational Review, 84(4), 505-531. https://doi.org/10.17763/haer.84.4.brr34733723j648u

Signorella, M. L., Bigler, R. S., Liben, L. S. (1993). Developmental differences in children's gender schemata about others: a meta-analytic review. Development Review, 13, 147-83. https://doi.org/10.1006/drev.1993.1007

Steele, C. M. (1997). A threat in the air: How stereotypes shape intellectual identity and performance. American Psychologist, 52, 613- 629. https://doi.org/10.1037/0003-066X.52.6.613

Sullivan, A. A. (2016). Breaking the STEM Stereotype: Investigating the use of robotics to change young children's gender stereotypes about technology and engineering. Tufts University, Medford, MA. https://doi.org/10.1145/2771839.2771868

Sullivan, A. and Bers, M. U. (2017). Dancing robots: Integrating art, music, and robotics in Singapore's early childhood centers. International Journal of Technology and Design Education. Online First. https://doi..org/10.1007/s10798-017-9397-0

Sullivan, A., Elkin, M. and Bers, M. U. (2015). KIBO Robot Demo: Engaging young children in programming and engineering. In Proceedings of the 14th International Conference on Interaction Design and Children (IDC '15). ACM, Boston, MA, USA.

Strawhacker, A., Portelance, D., Lee, M. and Bers, M.U. (2015). Designing Tools for Developing Minds: The role of child development in educational technology. In Proceedings of the 14th International Conference on Interaction Design and Children (IDC '15). ACM, Boston, MA, USA. 
Strong-Wilson, T. and Ellis, J. (2007). Children and place: Reggio Emilia's environment as third teacher. Theory into practice, 46(1), 40-47. https:/ / doi.org/10.1080/00405840709336547

Syvertsen, J. and Pigozzi, A. O. D. W. (2010). The third teacher: 79 ways you can use design to transform teaching \& learning. Abrams.

Turkle, S. (2016). Reclaiming conversation: The power of talk in a digital age. Penguin.

Vygotsky, L. (1963). Thought and language. Cambridge, MA: MIT Press. (Translation of Russian original, published 1934.)

Wang, F., Wang, W., Wilson, S. and Ahmed, N. (2016). The state of library makerspaces. International Journal of Librarianship, 1(1), 2-16. https://doi.org/10.23974/ijol.2016.vol1.1.12

Wartella, E. A. and Jennings, N. (2000). Children and computers: New technology. Old concerns. The future of cbildren, 31-43. https://doi.org/10.2307/1602688

Wyeth, P. (2008). How young children learn to program with sensor, action, and logic blocks. Journal of the Learning Sciences, 17(4), 517-550. https://doi.org/10.1080/10508400802395069

Yelland, N. (2005). The Future Is Now: A Review of the Literature on the Use of Computers in Early Childhood Education (1994 - 2004). AACE Journal, 13(3), 201-232. Norfolk, VA: Association for the Advancement of Computing in Education (AACE). Available at: https:/ /www.learntechlib.org/p/6038 (Accessed 28 February, 2018)

\section{APPENDIX A}

\section{Positive Technological Development (PTD) Engagement Checklist: Environment \& Facilitator}

\section{What is the Checklist?}

The PTD Engagement Checklist is based on the theoretical foundation of Positive Technological Development (PTD). The PTD framework guides the development, implementation and evaluation of educational programs that use new technologies to promote learning as an aspect of positive youth development. The PTD framework is a natural extension of the computer literacy and the technological fluency movements that have influenced the world of education, but adds psychosocial and ethical components to the cognitive ones. From a theoretical perspective, PTD is an interdisciplinary approach that integrates ideas from the fields of computer-mediated communication, computer-supported collaborative learning, and the Constructionist theory of learning developed by Seymour Papert (1993), and views them in light of research in applied development science and positive youth development.

As a theoretical framework, PTD proposes six positive behaviors (six C's) that should be supported by educational programs that use new technologies and innovations, such as the Eliot-Pearson Maker Space. These behaviors are: communication, collaboration, community building, content creation, creativity, and choice of conduct.

More information about PTD can be found in Marina Umaschi Bers' book Designing Digital Experiences for Positive Youth Development: From Playpen to Playground (2012).

\section{How is the Checklist used?}

The PTD Engagement Checklist is designed for use in a variety of settings where children are engaging with technology. It is divided into six sections (each one representing a behavior described in the PTD framework) and measured using a 5-point Likert scale. The checklist is meant to evaluate a learning environment and teacher/facilitator while children are working within the space. Adults may use the checklist as often as multiple times during each lesson, or as infrequently as once per unit. The goal of the PTD checklist is to provide a lens into how children are engaging with the space and experimenting with the behaviors described by the PTD framework. 
European Journal of STEM Education, 2018, 3(3), 09

\begin{tabular}{|c|c|c|c|c|c|c|}
\hline $\begin{array}{l}\text { On a scale from } 1 \text { to } 5 \text { (with } 1=\text { Never and } 5=\text { Always), how often do students do } \\
\text { the following? Please select one. }\end{array}$ & $\begin{array}{c}1 \\
\text { Never }\end{array}$ & $\begin{array}{l}2 \\
\text { Almost } \\
\text { Never }\end{array}$ & $\begin{array}{c}3 \\
\text { Some- } \\
\text { times }\end{array}$ & $\begin{array}{c}4 \\
\text { Often }\end{array}$ & $\begin{array}{c}5 \\
\text { Always }\end{array}$ & $\begin{array}{l}\text { N/A or } \\
\text { Not Observable }\end{array}$ \\
\hline \multicolumn{7}{|l|}{ Communication } \\
\hline \multicolumn{7}{|l|}{$\begin{array}{l}\text { The arrangement of the space allows for children to see one another's work. } \\
\text { - There are low or no barriers between activity spaces }\end{array}$} \\
\hline \multicolumn{7}{|l|}{$\begin{array}{l}\text { The arrangement of the space allows for children to talk with one another. } \\
\text { - Workspaces are arranged so that children can facing one another } \\
\text { - Children in different areas communicate at normal volume }\end{array}$} \\
\hline $\begin{array}{l}\text { The Facilitator(s) is engaging children in two-way conversations } \\
\text { - Facilitator asks children open-ended questions } \\
\text { - Facilitator pauses to let children respond }\end{array}$ & & & & & & \\
\hline
\end{tabular}

\section{Collaboration}

The arrangement of the space promotes sharing of tools/materials.

- Materials are arranged in a central area for children to use and return

- Tools are not designed for one child to use alone (e.g. heavy blocks that need two people, tools with many

parts or steps)

The arrangement of the space allows for multiple children to work on one project.

- Workspaces include large floor areas, round tables with multiple chairs, etc.

Facilitator invites children to work together

- Facilitator suggests that children seek, help from peers

Comments:

\begin{tabular}{|c|c|c|c|c|c|c|}
\hline $\begin{array}{l}\text { On a scale from } 1 \text { to } 5 \text { (with } 1=\text { Never and } 5=\text { Always), how often do students do } \\
\text { the following? }\end{array}$ & $\begin{array}{c}1 \\
\text { Never }\end{array}$ & $\begin{array}{c}2 \\
\text { Almost } \\
\text { Never }\end{array}$ & $\begin{array}{c}3 \\
\text { Some- } \\
\text { times } \\
\end{array}$ & $\begin{array}{c}4 \\
\text { Often }\end{array}$ & $\begin{array}{c}5 \\
\text { Always }\end{array}$ & $\begin{array}{c}\text { N/A or } \\
\text { Not Observable }\end{array}$ \\
\hline
\end{tabular}

Community Building Never times

There is evidence in the space of the children who use it

- There are images of children using the space

- There are objects labeled with the maker's name, or the story of how it was made

There is evidence in the space of the local location or context

- There are images, maps, etc that reference the neighborbood, school, or town where the space is located

- There is material representing holidays, seasons, or activities of the local culture

The Facilitator has a warm and friendly relationship with children

- Facilitator carries personal conversations with children (e.g. asking a student about their new pet)

- Facilitator provides support and encouragement as children work.

\section{Comments:}

\section{Content Creation}

Tools and materials are visible and accessible to children

- Materials are in clear containers, low baskets, or presented on tables

- Materials are stored at children's height and can be easily reached

There are locations in the space to present or document children's work.

- There are pictures and explanations of children's work

- There is a space for ongoing work to stay

Facilitator models content creation

- Facilitator works on projects alongside children, or assists when asked

- Facilitator shares mistakes openly and models how to cope with them

\section{Comments:}

\begin{tabular}{|c|c|c|c|c|c|c|}
\hline $\begin{array}{l}\text { On a scale from } 1 \text { to } 5 \text { (with } 1=\text { Never and } 5=\text { Always), how often do students do } \\
\text { the following? }\end{array}$ & $\begin{array}{c}1 \\
\text { Never }\end{array}$ & $\begin{array}{c}2 \\
\text { Almost } \\
\text { Never }\end{array}$ & $\begin{array}{c}3 \\
\text { Some- } \\
\text { times } \\
\end{array}$ & $\begin{array}{c}4 \\
\text { Often }\end{array}$ & $\begin{array}{c}5 \\
\\
\text { Always }\end{array}$ & $\begin{array}{c}\text { N/A or } \\
\text { Not Observable }\end{array}$ \\
\hline
\end{tabular}

\section{Creativity}

There are areas and materials within the space that encourage wonder

- There are beautiful, colorful, or textured objects clearly located around the room

- There are spaces for children that are cosy, soft, or private

Materials/Tools are presented that can be used in more than one way

- There are bins of miscellaneous crafts

- There is evidence of the same material/ tool being used in many ways

Facilitator encourages a diversity of approaches in children's work

- Facilitator models using criteria to compare work. (e.g. "I see that this method is more X, but your other

idea is more Y")

- Facilitator allows children to change ideas as they work

\section{Comments:}

\section{Choice of Conduct}

Tools/materials are offered that require children to use with care

- Materials and containers that are breakable or delicate

- Tools that have sharp edges, or require focused attention to use

There is evidence in the space of the values of those who use it

- There projects or wall art related to value words (e.g. Respect, Caring)

- There are rule charts or images of behavior choices

Facilitator engage children in non-judgmental conversation about choices

- Facilitator moderates children having a disagreement to observe and converse with each other to reach a solution

- Facilitator reinforces children's sense of character, e.g., 'You're the kind of girl who knows how to be nice

to ber friends"

Comments: 


\section{Positive Technological Development (PTD) Engagement Checklist: Children/Child}

\section{What is the Checklist?}

The PTD Engagement Checklist is based on the theoretical foundation of Positive Technological Development (PTD). The PTD framework guides the development, implementation and evaluation of educational programs that use new technologies to promote learning as an aspect of positive youth development. The PTD framework is a natural extension of the computer literacy and the technological fluency movements that have influenced the world of education but adds psychosocial and ethical components to the cognitive ones. From a theoretical perspective, PTD is an interdisciplinary approach that integrates ideas from the fields of computer-mediated communication, computer-supported collaborative learning, and the Constructionist theory of learning developed by Seymour Papert (1993), and views them in light of research in applied development science and positive youth development.

As a theoretical framework, PTD proposes six positive behaviors (six C's) that should be supported by educational programs that use new technologies and innovations, such as the Eliot-Pearson Maker Space. These behaviors are: communication, collaboration, community building, content creation, creativity, and choice of conduct.

More information about PTD can be found in Marina Umaschi Bers' book Designing Digital Experiences for Positive Youth Development: From Playpen to Playground (2012).

\section{How is the Checklist used?}

The PTD Engagement Checklist is intended to be used in a variety of settings where children are engaging with technology. It is divided into six sections (each one representing a behavior described in the PTD framework) and measured using a 5-point Likert scale. The checklist is meant to evaluate a group of children or an individual child they work in a space. Adults may use the checklist as often as multiple times during each lesson, or as infrequently as once per unit. The goal of the PTD checklist is to provide a lens into how children are engaging with the space and experimenting with the behaviors described by the PTD framework. 
European Journal of STEM Education, 2018, 3(3), 09

the following? Please select one.

\begin{tabular}{|c|c|c|c|c|c|}
\hline Never & $\begin{array}{l}\text { Almost } \\
\text { Never }\end{array}$ & $\begin{array}{l}\text { Some- } \\
\text { times }\end{array}$ & Often & Always & Not Observable \\
\hline
\end{tabular}

Communication

Children are observing and/or engaging each other's work

- Children watch as others work on a project

- Children touch or play with each other's projects while they work.

Children are playing with each other or talking to each other

- Children speak or sign to each other

- Children ask each other what they are doing, request tools to be passed, etc.

Children engage in conversation (verbally or non-verbally) with adults

- Children speak, nod their head, etc. when adults pause to let them respond

\section{Comments:}

\section{Collaboration}

Children share tools/materials.

- Children to use materials and return them when done

- Children do not "collect" tools that they are not using

Children are working together on the same project.

- Cbildren are actively engaged in the same play/work activity

- Cbildren are adding elements to the same project

Children seek assistance from peers

- Children ask each other to hold things in place, help them move objects, etc.

- Children make suggestions to each other, ask each other to show them how they made something, etc.

\section{Comments:}

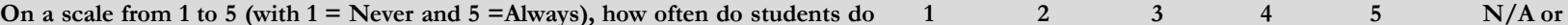
the following? Please select one. Never Almost Some- Often Always Not Observable

Community Building

Children share work with others

- Children show work to peers or facilitators

- Children place work on display somewhere in the space (or, they request/allow facilitators display their

work.)

Children work on projects related to their local environment

- Children make robots to belp their school, plows for the winter snow in their neighborbood, etc.

- Children read books, ask questions, or role play about local holidays, events, or locations

Children are warm and friendly with each other

- Children ask each other about bome, or speak about each other's personal details (e.g. "I saw your sister

in the ballway")

- Children laugh and play together

\section{Comments:}

\section{Content Creation}

Children gather tools and materials without much assistance

- Children reach for crafts or turn on computers without needing belp

- Children open boxes or bring tools out on their own

Children show focus and sustained attention while working

- Children build a tower, color and craft a flower, program a stor

- Children work steadily on this project over several minutes,

Children iterate on projects

- Children return to projects again and again, over one or more sessions

- Children change their artifacts without starting a new one

\section{Comments}

\begin{tabular}{|c|c|c|c|c|c|c|}
\hline $\begin{array}{l}\text { On a scale from } 1 \text { to } 5 \text { (with } 1=\text { Never and } 5=\text { Always), how often do students do } \\
\text { the following? }\end{array}$ & $\begin{array}{c}1 \\
\text { Never }\end{array}$ & $\begin{array}{c}2 \\
\text { Almost } \\
\text { Never }\end{array}$ & $\begin{array}{c}3 \\
\text { Some- } \\
\text { times }\end{array}$ & $\begin{array}{c}4 \\
\text { Often }\end{array}$ & $\begin{array}{c}5 \\
\text { Always }\end{array}$ & $\begin{array}{c}\text { N/A or } \\
\text { Not Observable }\end{array}$ \\
\hline
\end{tabular}

Children are observing, touching, or manipulating objects in the space

- Children run their fingers over a plush cusbion or hold glass beads up to the light

- Children comment about the properties of an object (e.g. "this wood is rough")

Children use a variety of materials while they work

- Children use wires, glitter, and cloth in a collage

- Children mix materials from different areas (e.g. blocks with crafts)

Children try a variety of approaches in the same task

- Cbildren try tape, paper clips, and hot glue guns to attach paper

- Children try building a tower on a table, a chair, and a cushion

\section{Comments.}

\section{Choice of Conduct}

Children handle tools/materials with care

- Children carefully hold/ use scissors, glass, etc.

- Children return dangerous tools safely after using them.

Children show respect to the space

- Children clean up materials after they are done working

- Children use furniture, technology, etc. in safe ways

Children show respect to each other

- Children take turns, share materials, and give each other space

- Children show signs of character (e.g. bugging someone who is crying, belping someone else clean up a mess)

Comments: 